\title{
Urea-Functionalized Poly(ionic liquid) Photonic Spheres for Visual Identification of Explosives with a Smartphone
}

Chengcheng Liu, ${ }^{\ddagger}, a$ Wanlin Zhang, ${ }^{\ddagger}, a$ Yang Zhao, ${ }^{b}$ Changxu Lin, ${ }^{c}$ Kang Zhou, ${ }^{a}$ Yanmei Li, ${ }^{a}$

Guangtao Li,a

a. Department of Chemistry, Tsinghua University, Beijing 100084, P. R. China

b. Institute of Forensic Science, Ministry of Public Security, Beijing 100038, P. R. China

c. Research Institute for Biomimetics and Soft Matter, Fujian Provincial Key Laboratory for Soft Functional Materials Research, College of Physical Science and Technology, Xiamen University, Xiamen 361005, P. R. China

* E-mail: 1gt@mail.tsinghua.edu.cn.

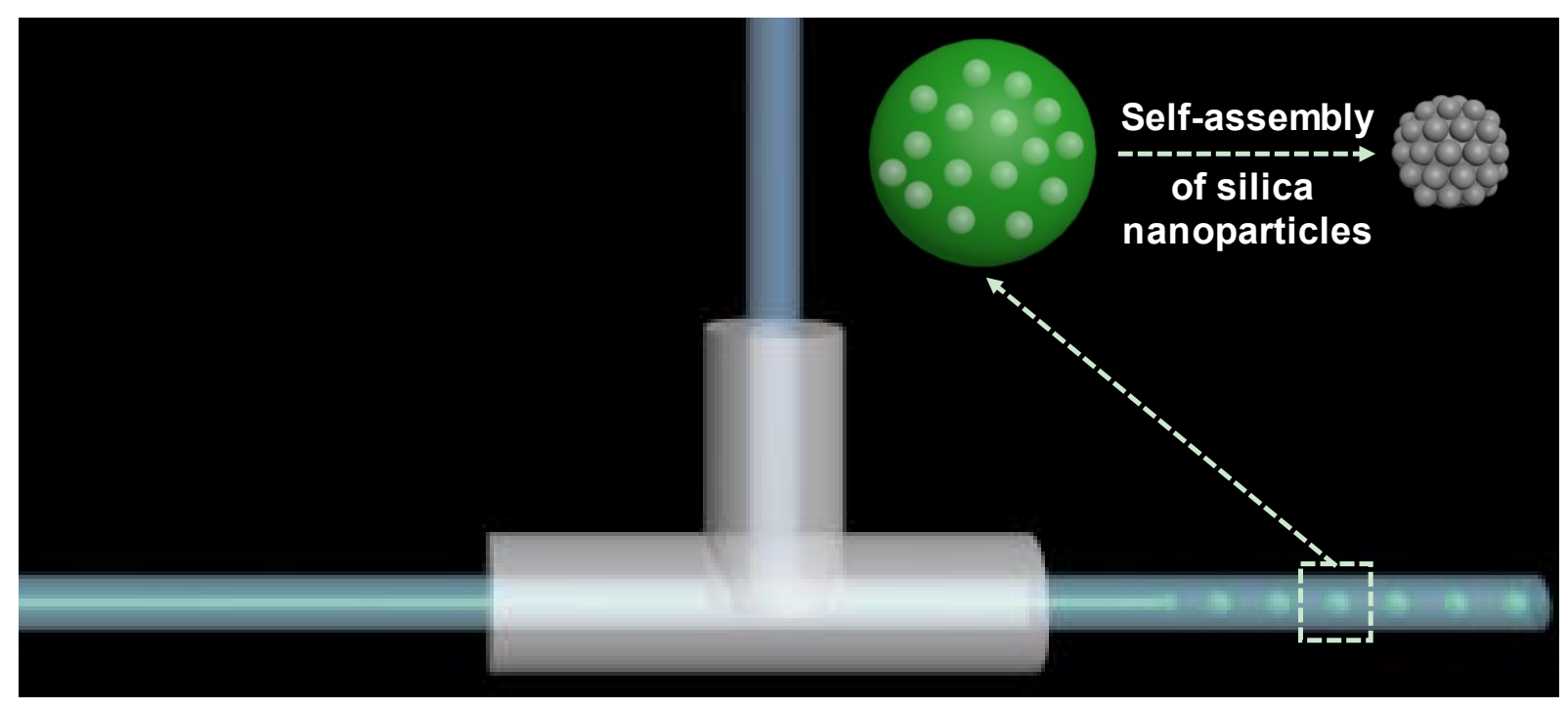

Figure S1. Schematic illustration of the preparation of photonic crystal sphere templates by droplet-based microfluidics. 
Imidazolium-based ionic liquid monomer (IL monomer, i.e.1-(3-(3-butylurea) propyl)-3-(4vinylbenzyl)-1H-imidazol-3-ium chloride) and crosslinker (IL crosslinker, i.e.1-1'(5,14-dioxo4,6,13,15-tetraazaocdadecane-1,18-diyl) bis (3-(4-vinylbenzyl)-1H-imidazol-3-ium) chloride) were synthesized. ${ }^{1}$

(a)
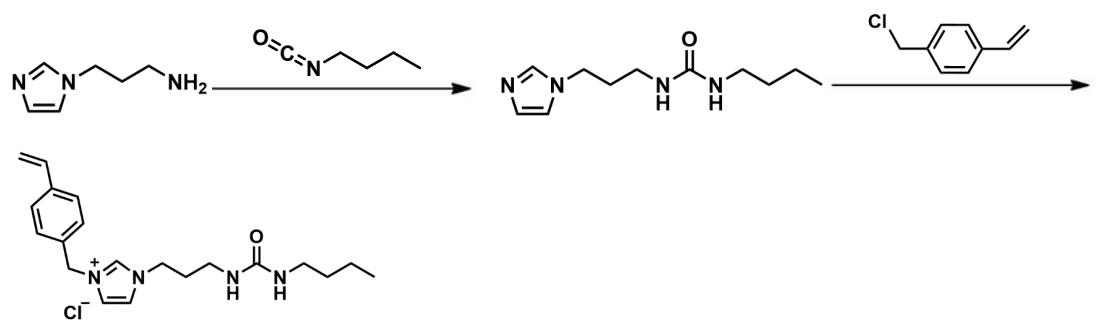

(b)
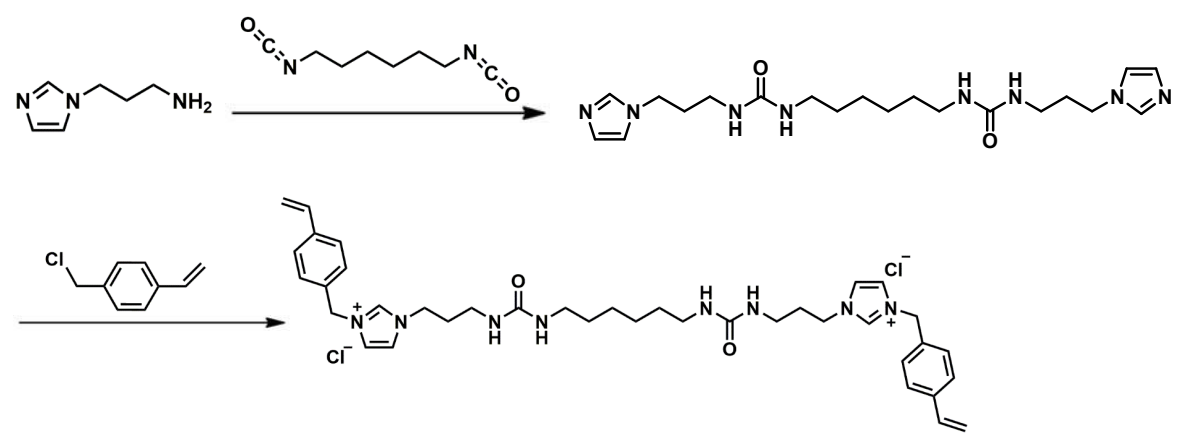

Figure S2. Synthetic routes to urea-functionalized imidazolium-based ionic liquid monomer (a) and crosslinker (b).

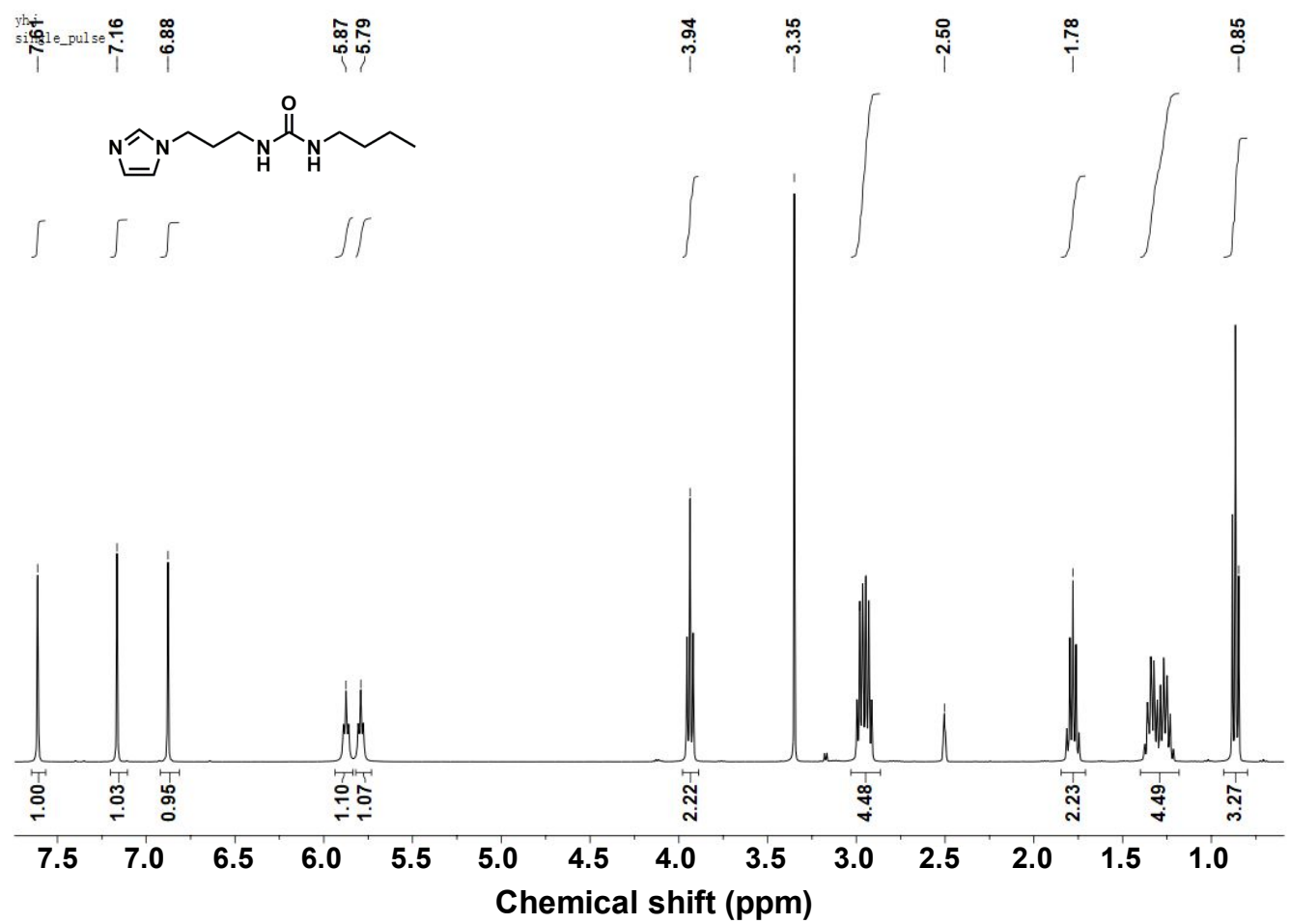


${ }^{1} \mathrm{H}$ NMR spectrum of compound 1 in DMSO- $d_{6}$.

Synthesis of compound 1. N-(3-Aminopropyl)-imidazole $(5.0 \mathrm{~g}, 40 \mathrm{mmol})$ was mixed with $25 \mathrm{~mL}$ acetonitrile under atmosphere of dry nitrogen. Butyl isocyanate $(4.35 \mathrm{~g}, 44 \mathrm{mmol})$ dissolved in 6.5 $\mathrm{mL}$ acetonitrile was added to the stirred solution in the dropwise fashion. The combined solution was stirred overnight, and then the solution was rotary evaporated. The residue was washed twice with diethyl ether, then the solvent was removed in vacuo. ${ }^{1} \mathrm{H}$ NMR (400 MHz, DMSO- $\left.d_{6}\right): \delta$, ppm: $7.61(1 \mathrm{H}, \mathrm{s}), 7.16(1 \mathrm{H}, \mathrm{s}), 6.88(1 \mathrm{H}, \mathrm{s}), .5 .87(1 \mathrm{H}, \mathrm{t}, \mathrm{J}=5.6 \mathrm{~Hz}), 5.79(1 \mathrm{H}, \mathrm{t}, \mathrm{J}=6 \mathrm{~Hz}), 3.94(2 \mathrm{H}, \mathrm{t}, \mathrm{J}$ $=6.8 \mathrm{~Hz}), 3.0-2.91(4 \mathrm{H}, \mathrm{m}, \mathrm{J}=7.2 \mathrm{~Hz}), 1.81-1.75(2 \mathrm{H}, \mathrm{m}, \mathrm{J}=6.8 \mathrm{~Hz}), 1.38-1.21(4 \mathrm{H}, \mathrm{m}, \mathrm{J}=7.6 \mathrm{~Hz})$, $0.86(3 \mathrm{H}, \mathrm{t}, \mathrm{J}=7.2 \mathrm{~Hz})$.

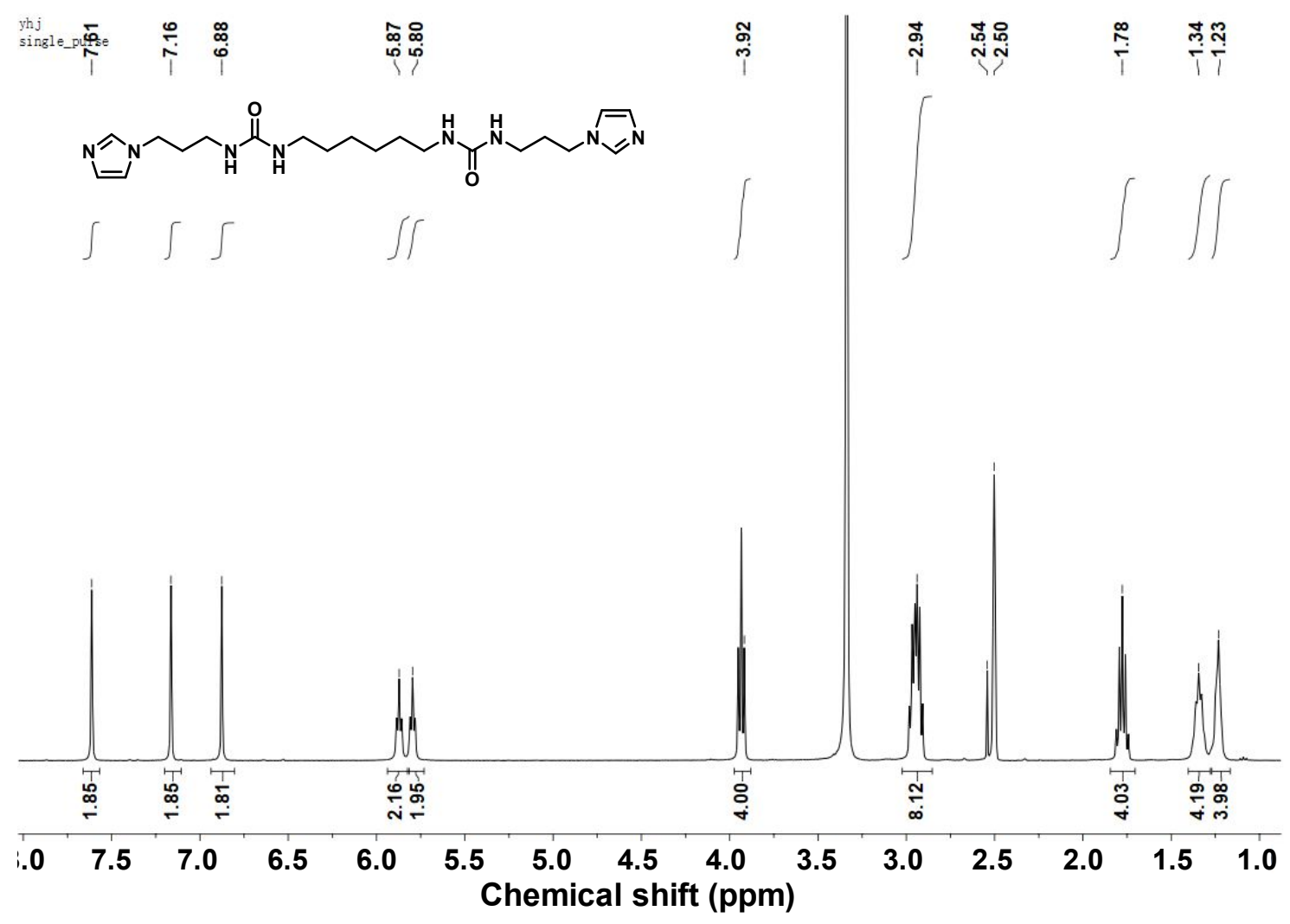

${ }^{1} \mathrm{H}$ NMR spectrum of compound 2 in DMSO- $d_{6}$.

Synthesis of compound 2. N-(3-Aminopropyl)-imidazole $(6.259 \mathrm{~g}, 50 \mathrm{mmol})$ was mixed with 40 $\mathrm{mL}$ acetonitrile under atmosphere of dry nitrogen. Hexamethylene Diisocyanate $(1.68 \mathrm{~g}, 10 \mathrm{mmol})$ was added to the stirred solution in the dropwise fashion very slowly. The combined solution was 
stirred overnight, and then the mixture was filtrated under reduced pressure to get the white solid. Then the solid was dissolved in dimethylsulfoxide and the mixture was washed three times with diethyl ether, then the solvent was removed in vacuo to ensure complete dryness of the solid product. ${ }^{1} \mathrm{H}$ NMR $\left(400 \mathrm{MHz}\right.$, DMSO- $\left.d_{6}\right): \delta$, ppm: $7.61(2 \mathrm{H}, \mathrm{s}), 7.16(2 \mathrm{H}, \mathrm{s}), 6.88(2 \mathrm{H}, \mathrm{s}), 5.87(2 \mathrm{H}, \mathrm{t}$, $\mathrm{J}=5.6 \mathrm{~Hz}), 5.8(2 \mathrm{H}, \mathrm{t}, \mathrm{J}=5.6 \mathrm{~Hz}), 3.93(4 \mathrm{H}, \mathrm{t}, \mathrm{J}=6.8 \mathrm{~Hz}), 2.98-2.91(8 \mathrm{H}, \mathrm{m}, \mathrm{J}=4.8 \mathrm{~Hz}), 1.81-1.74$ $(4 \mathrm{H}, \mathrm{m}, \mathrm{J}=6.8 \mathrm{~Hz}), 1.34(4 \mathrm{H}, \mathrm{t}, \mathrm{J}=6.4 \mathrm{~Hz}), 1.23(4 \mathrm{H}, \mathrm{s})$.

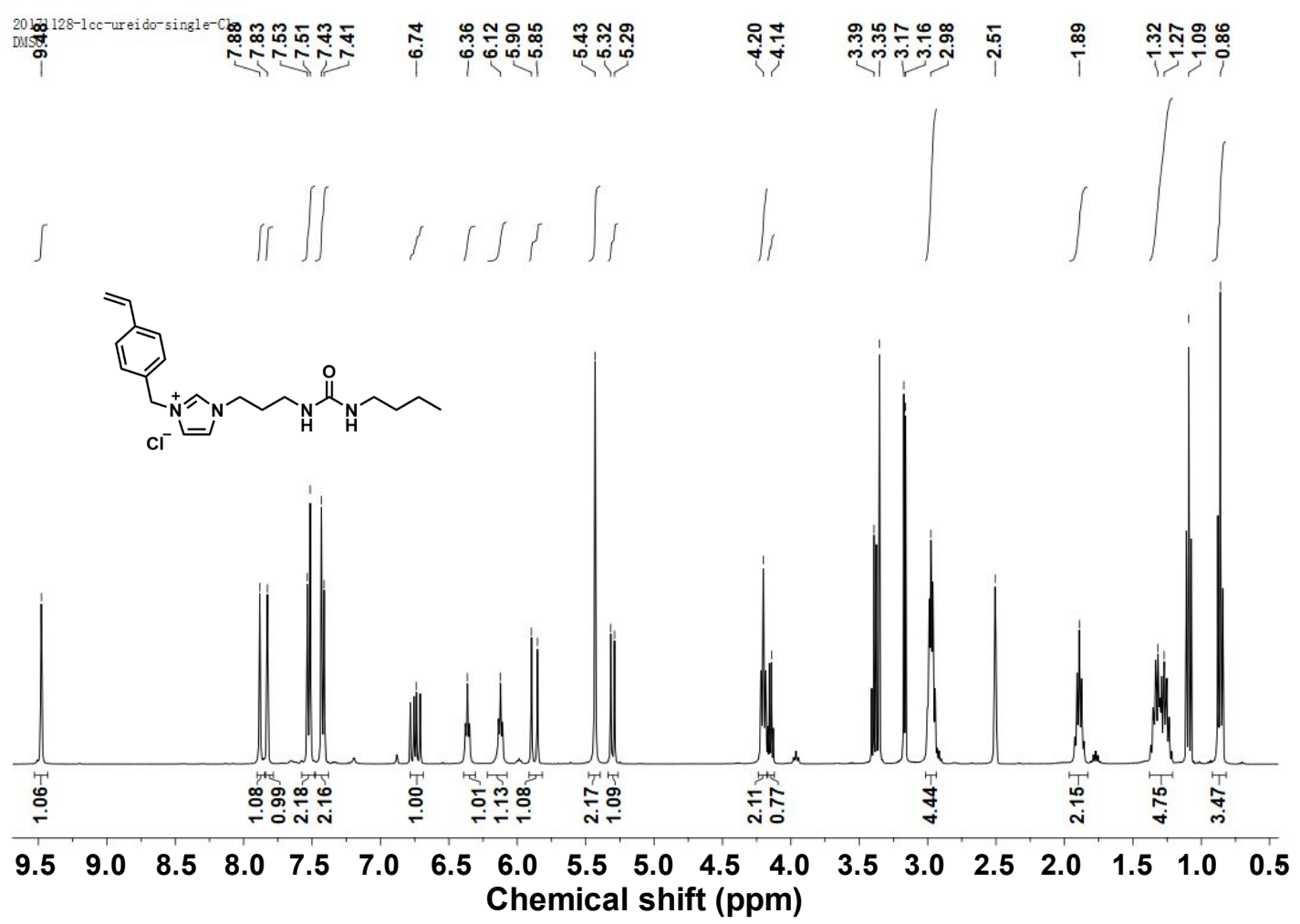

${ }^{1} \mathrm{H}$ NMR spectrum of IL monomer in DMSO- $d_{6}$.

Synthesis of IL monomer. The compound $1(0.224 \mathrm{~g}, 1 \mathrm{mmol})$ was dissolved in $5 \mathrm{~mL}$ acetonitrile under atmosphere of dry nitrogen. 4-vinylbenzyl chloride $(0.305 \mathrm{~g}, 2 \mathrm{mmol})$ was added to the stirred solution. The mixture was stirred for 12 hours at $50{ }^{\circ} \mathrm{C}$ with refluxing. The solution was rotary evaporated and then the residue was dissolved in methanol, and the mixture was washed three times with diethyl ether, then the solvent was removed in vacuo, leaving a sticky residue. ${ }^{1} \mathrm{H}$ NMR (400 MHz, DMSO- $\left.d_{6}\right): \delta$, ppm: $9.47(1 \mathrm{H}, \mathrm{s}), 7.88(1 \mathrm{H}, \mathrm{s}), 7.82(1 \mathrm{H}, \mathrm{s}), 7.53(2 \mathrm{H}, \mathrm{d}, \mathrm{J}=8 \mathrm{~Hz}), 7.42$ 
$(1 \mathrm{H}, \mathrm{d}, \mathrm{J}=8 \mathrm{~Hz}), 6.74(1 \mathrm{H}, \mathrm{dd}), 6.36(1 \mathrm{H}, \mathrm{t}, \mathrm{J}=6), 6.12(1 \mathrm{H}, \mathrm{t}, \mathrm{J}=5.6), 5.90-5.85(1 \mathrm{H}, \mathrm{dd}), 5.43$ $(2 \mathrm{H}, \mathrm{s}), 5.32-5.29(1 \mathrm{H}, \mathrm{dd}), 4.20(2 \mathrm{H}, \mathrm{t}, 6.8), 3.00-2.95(4 \mathrm{H}, \mathrm{m}), 1.93-1.86(2 \mathrm{H}, \mathrm{m}), 1.37-1.22(4 \mathrm{H}$, m), $0.86(3 \mathrm{H}, \mathrm{t}, \mathrm{J}=7.2) .{ }^{13} \mathrm{C}$ NMR (100 MHz, DMSO-d $\left.d_{6}\right): \delta, p p m: 158.44,137.58,136.48,136.01$, $134.35,128.81,126.70,122.94,122.48,115.25,79.40,51.69,48.54,46.89,43.9035 .83,32.22$, 30.59, 19.63, 13.79. MS: calcd. for $\left[\mathrm{C}_{20} \mathrm{H}_{29} \mathrm{~N}_{4} \mathrm{O}\right]^{+}: 341.2336$; found: 341.2334 .

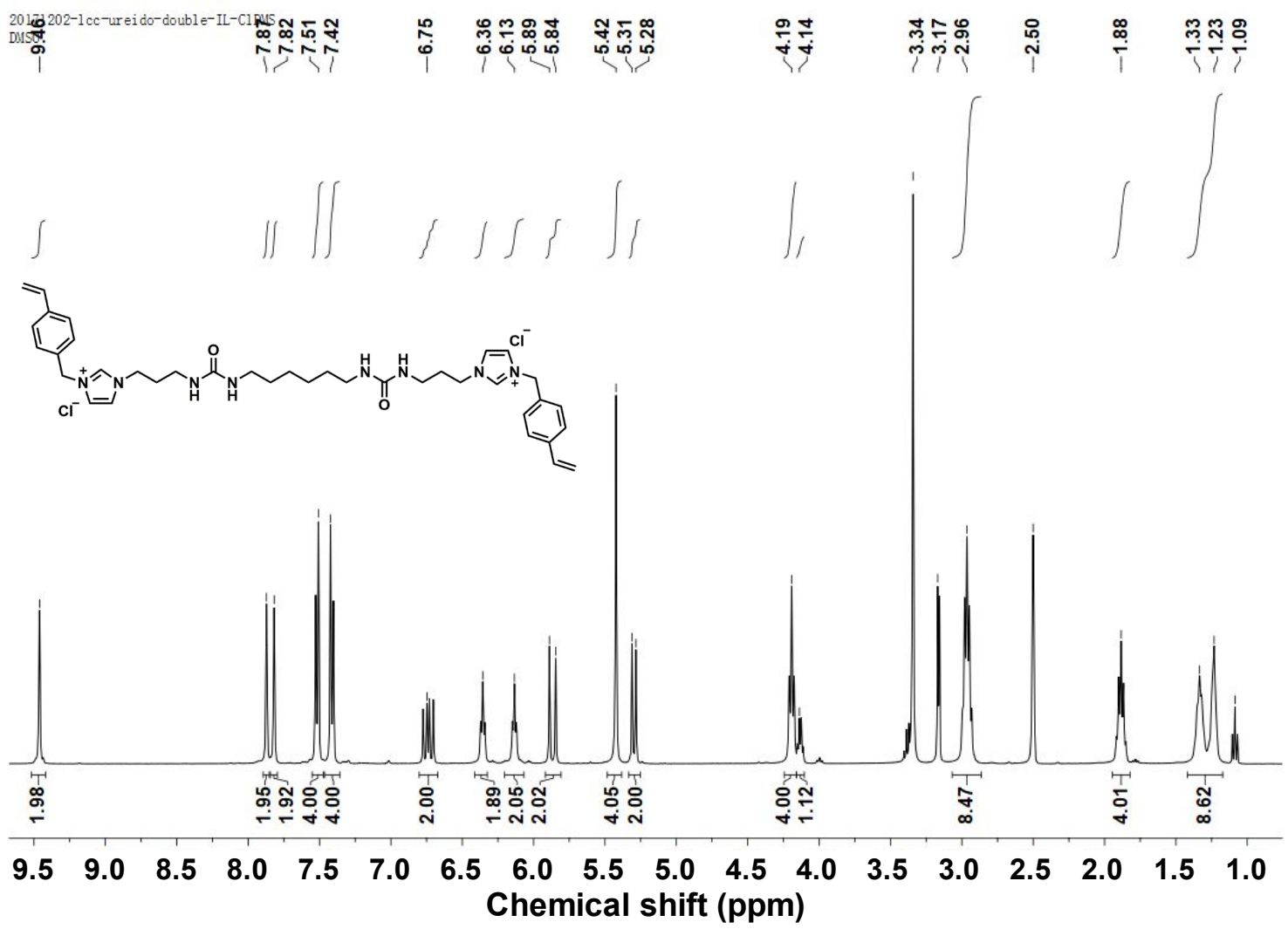

${ }^{1} \mathrm{H}$ NMR spectrum of IL crosslinker in DMSO- $d_{6}$.

Synthesis of IL crosslinker. The compound $2(0.209 \mathrm{~g}, 0.5 \mathrm{mmol})$ was dissolved in $6 \mathrm{~mL}$ acetonitrile/chloroform (1:2 by volume) under atmosphere of dry nitrogen. 4-vinylbenzyl chloride $(0.2289 \mathrm{~g}, 1.5 \mathrm{mmol})$ was added to the stirred solution. The mixture was stirred for 12 hours at 50 ${ }^{\circ} \mathrm{C}$ with refluxing. The solution was rotary evaporated and then the residue was dissolved in methanol, and the mixture was washed three times with diethyl ether, then the solvent was removed in vacuo, leaving a sticky residue. ${ }^{1} \mathrm{H}$ NMR (400 MHz, DMSO- $\left.d_{6}\right): \delta, p p m: 9.42(2 \mathrm{H}, \mathrm{s}), 7.86(2 \mathrm{H}, \mathrm{s})$, $7.81(2 \mathrm{H}, \mathrm{s}), 7.53(2 \mathrm{H}, \mathrm{d}, \mathrm{J}=8.4 \mathrm{~Hz}), 7.42(2 \mathrm{H}, \mathrm{d}, \mathrm{J}=8 \mathrm{~Hz}), 6.74(2 \mathrm{H}, \mathrm{dd}), 6.27(2 \mathrm{H}, \mathrm{t}, \mathrm{J}=6), 6.08$ 
$(2 \mathrm{H}, \mathrm{t}, \mathrm{J}=5.6), 5.89-5.85(2 \mathrm{H}, \mathrm{dd}), 5.42(4 \mathrm{H}, \mathrm{s}), 5.32-5.29(2 \mathrm{H}, \mathrm{dd}), 4.19(4 \mathrm{H}, \mathrm{t}, 6.8), 3.00-2.93(8 \mathrm{H}$, m), 1.92-1.85 (4H, m), 1.36-1.33 (4H, m), $1.24(4 \mathrm{H}, \mathrm{m}) .{ }^{13} \mathrm{C}$ NMR (100 MHz, DMSO-d 6 ): $\delta, p p m:$ $158.35,137.57,136.42,135.97,134.27,128.71,126.69,122.93,122.47,115.31,51.70,48.55$, 46.90, 35.89, 30.61, 30.02, 26.21. MS: calcd. for $\left[\mathrm{C}_{38} \mathrm{H}_{52} \mathrm{~N}_{8} \mathrm{O}_{2}\right]^{2+:} 326.2101$; found: 326.2101 .

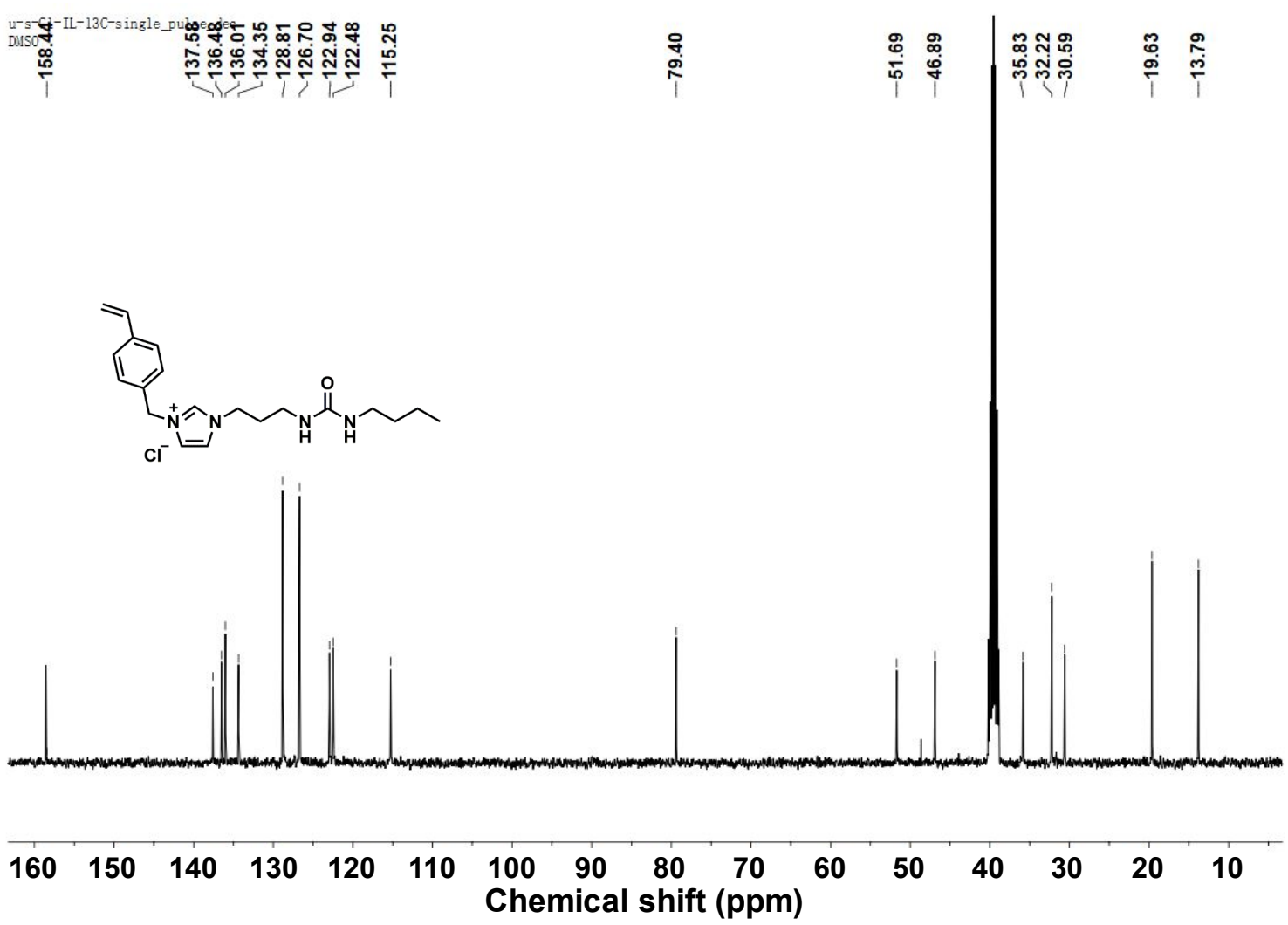

${ }^{13} \mathrm{C}$ NMR spectrum of IL monomer in DMSO- $d_{6}$. 


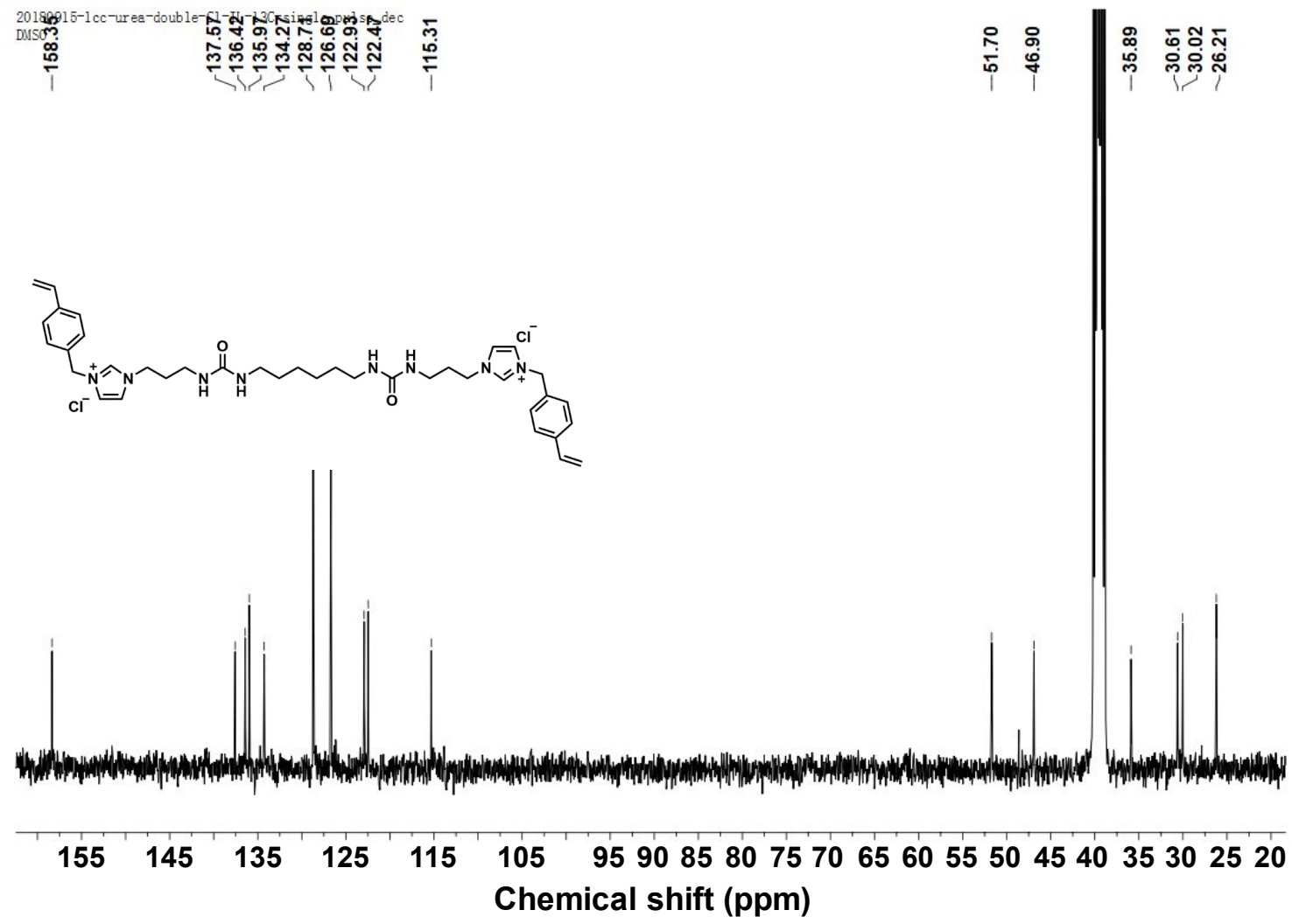

${ }^{13} \mathrm{C}$ NMR spectrum of IL crosslinker in DMSO- $d_{6}$.
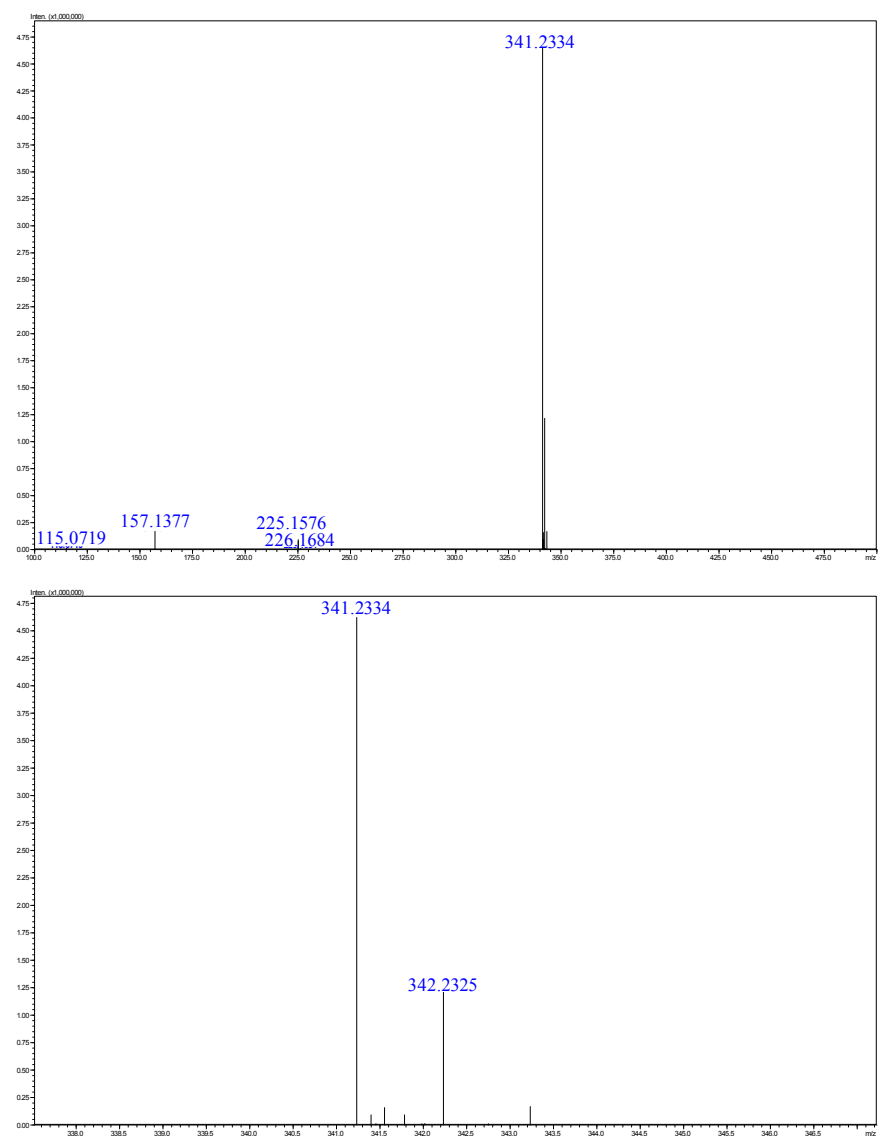

ESI-MS spectra of IL monomer. 

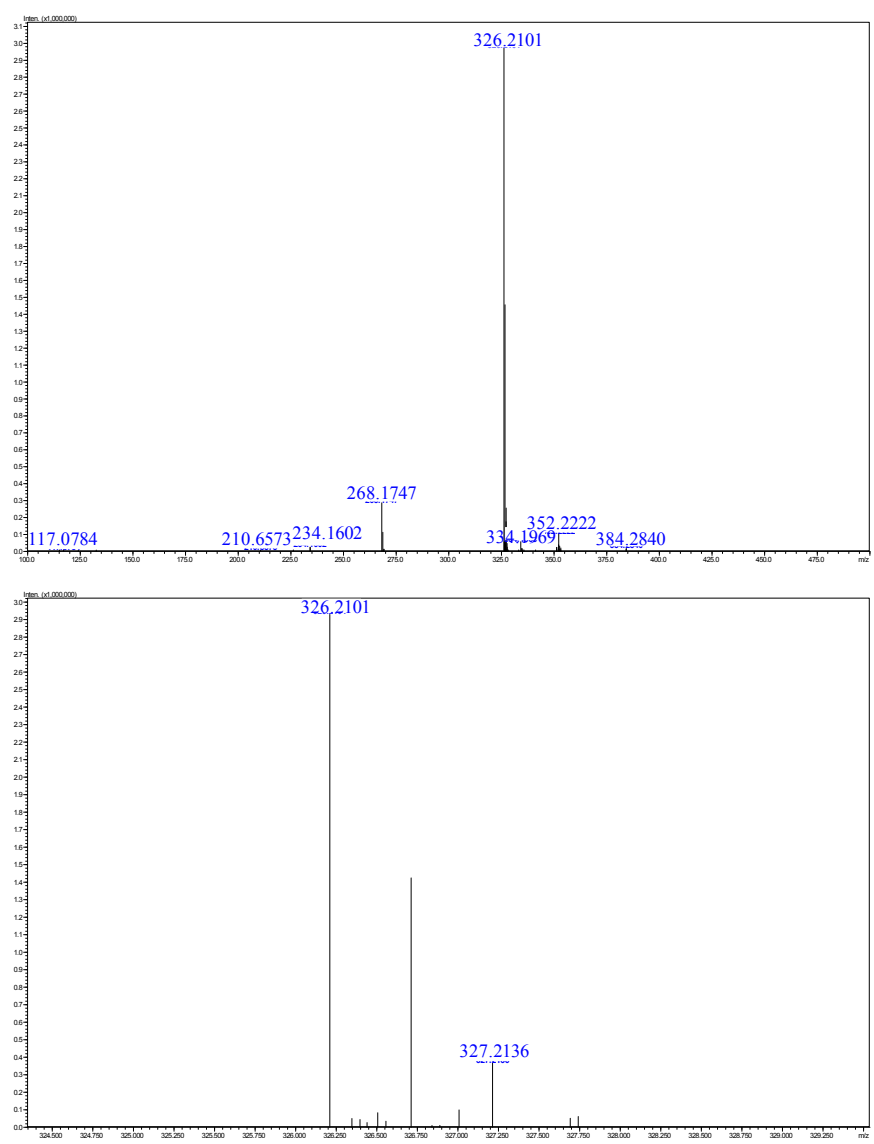

ESI-MS spectra of IL crosslinker.

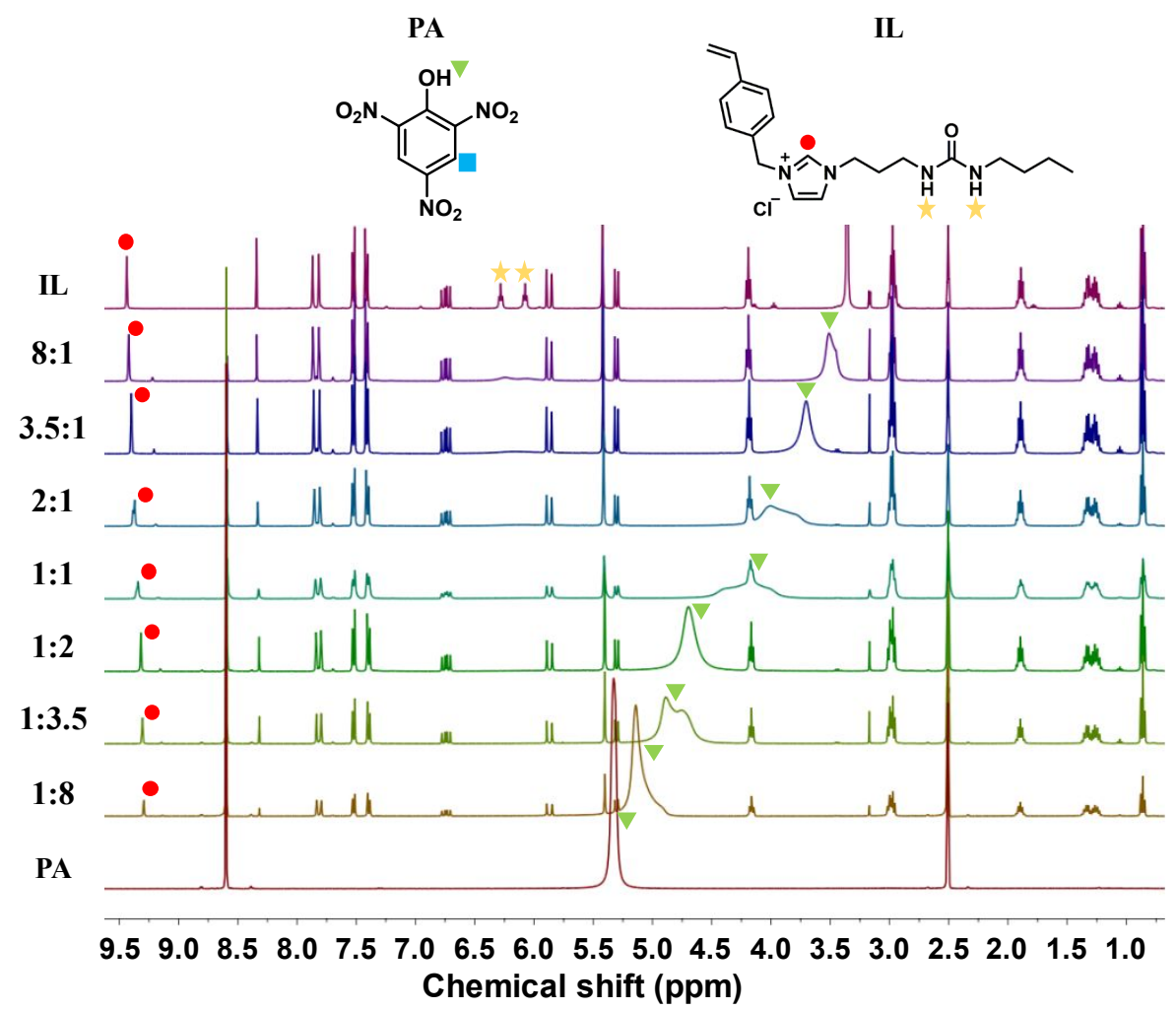

Figure S3. ${ }^{1} \mathrm{H}$ NMR $(400 \mathrm{MHz})$ titrations of IL monomer $(0.05 \mathrm{M})$ upon the addition of PA in DMSO- $d_{6}$. 

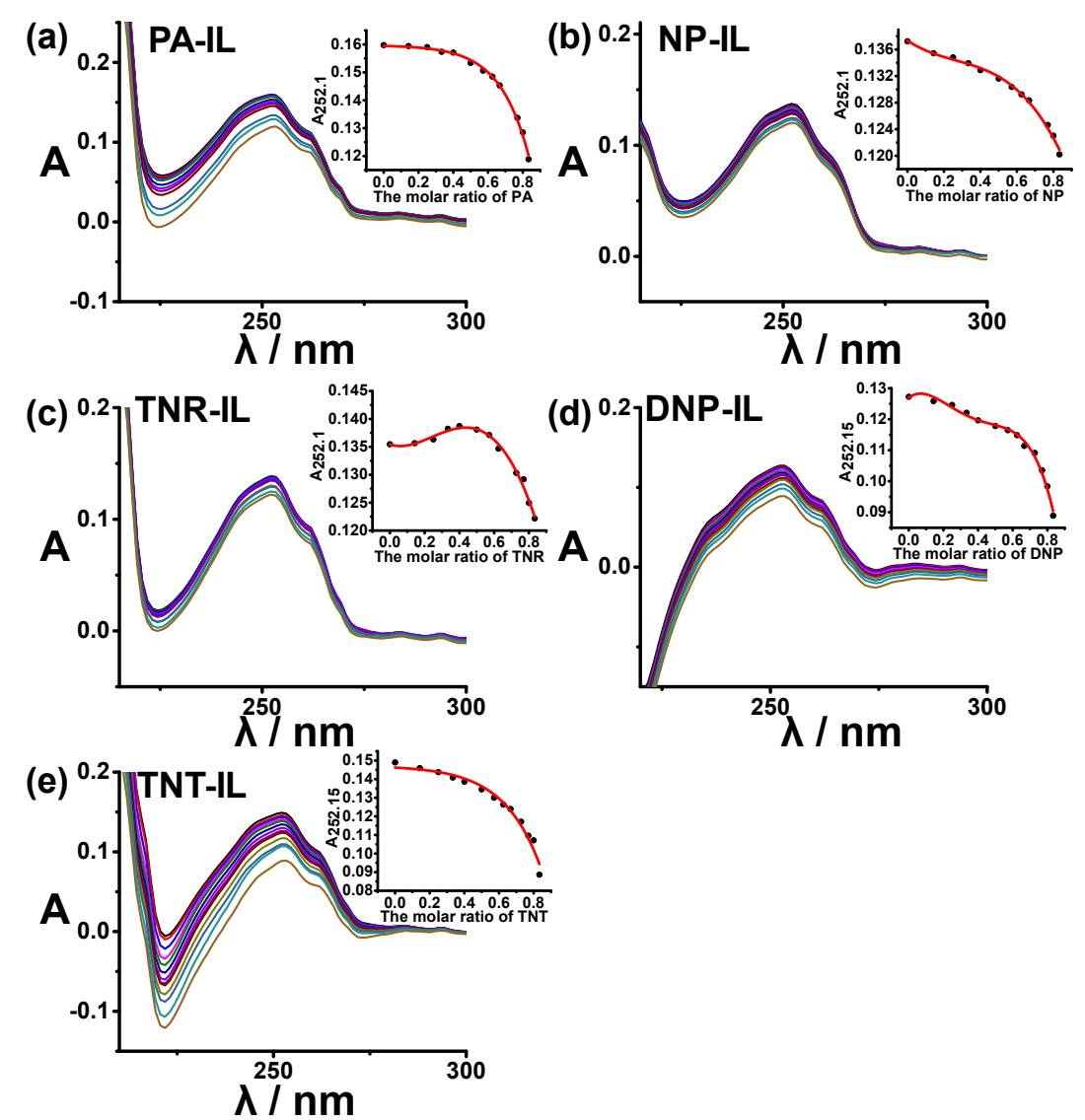

Figure S4. UV-vis titrations of IL monomer $(10 \mu \mathrm{M})$ upon the addition of (a) PA, (b) NP, (c) TNR, (d) DNP and (e) TNT in DMSO- $d_{6}$.

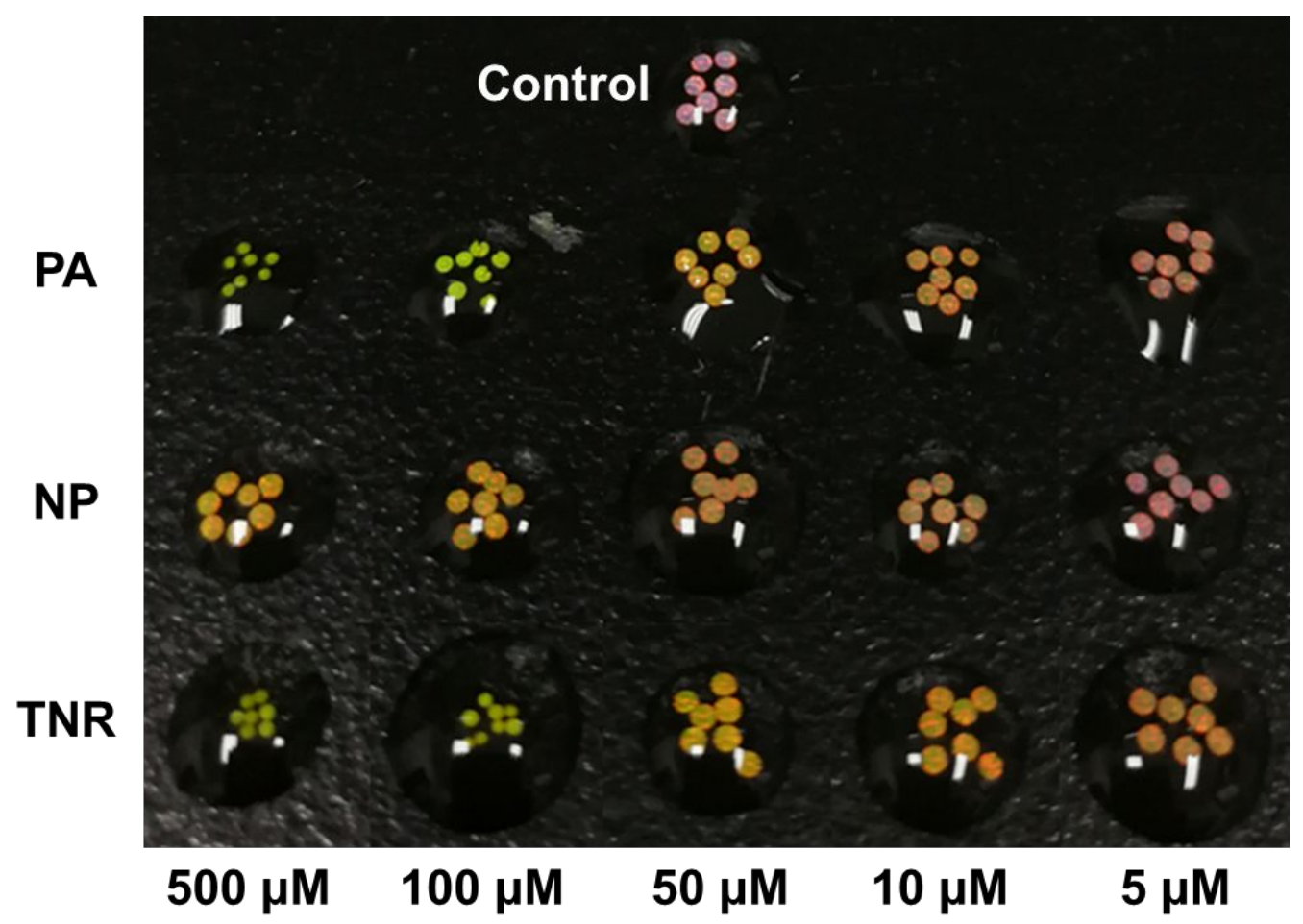

Figure S5. The photo of the PIL spheres before and after responding to the explosives at different concentrations. 
(a)

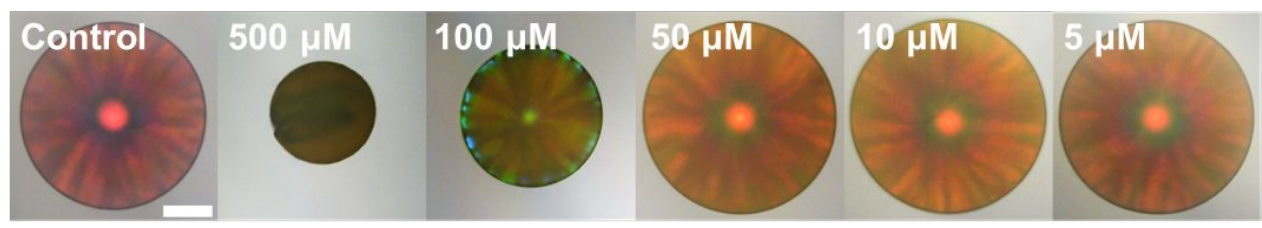

(b)

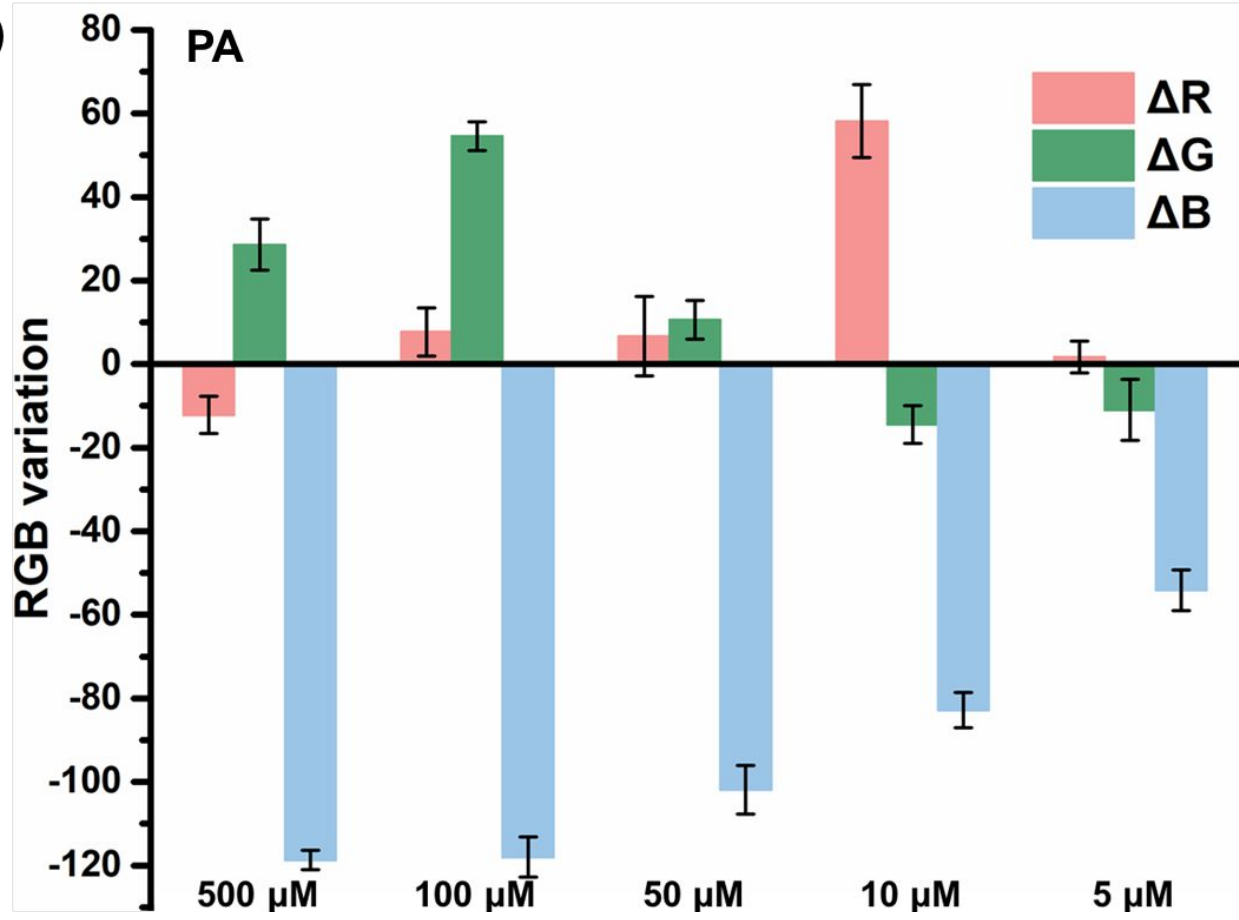

Figure S6. (a) The microscope optical images of the PIL spheres before and after binding PA at different concentrations (b) and the histogram of corresponding $\Delta \mathrm{RGB}$ data. The scale bar is $200 \mu \mathrm{m}$.

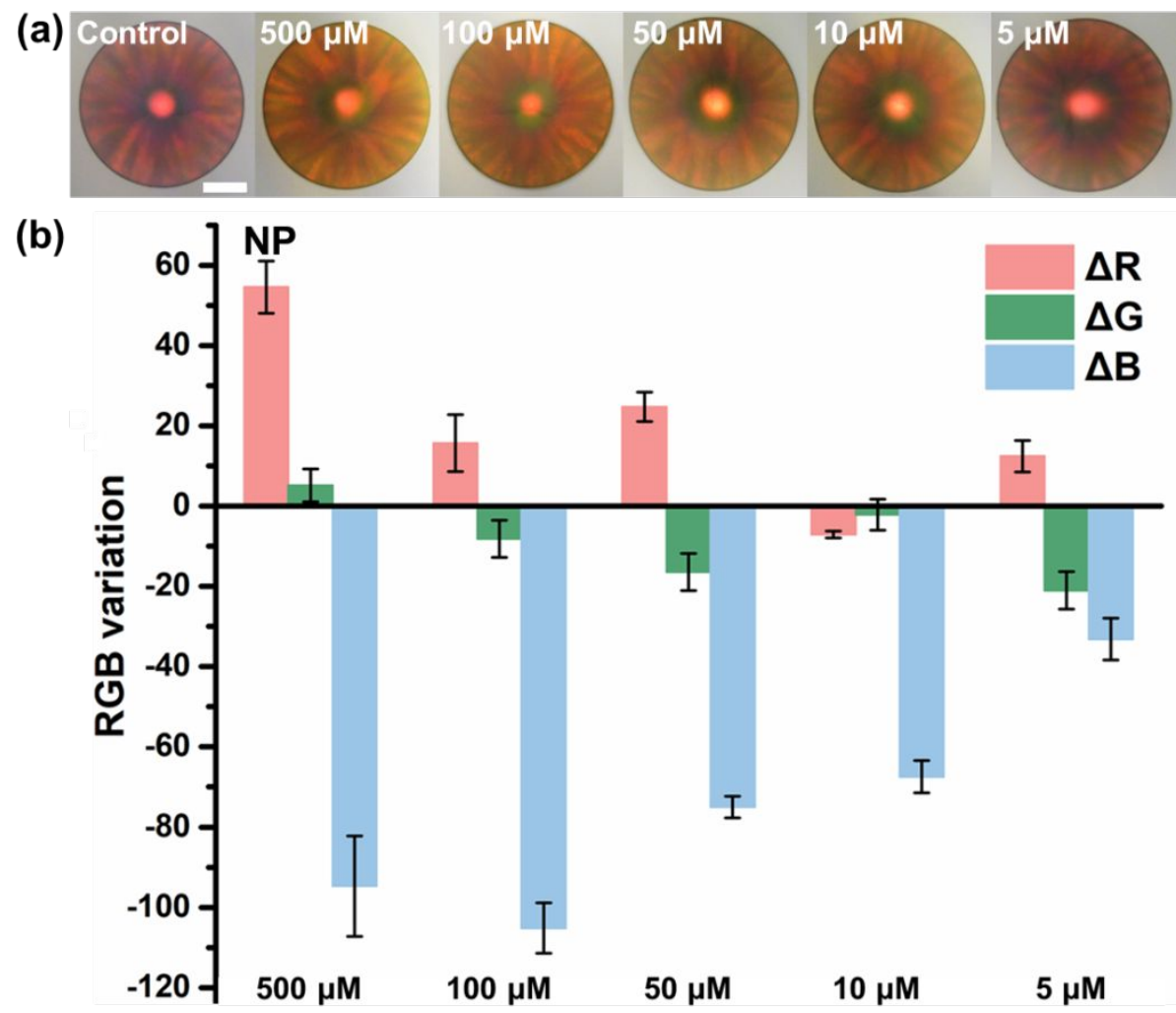

Figure S7. (a) The microscope optical images of the PIL spheres before and after binding NP at different 
concentrations and (b) the histogram of corresponding $\Delta$ RGB data. The scale bar is $200 \mu \mathrm{m}$.
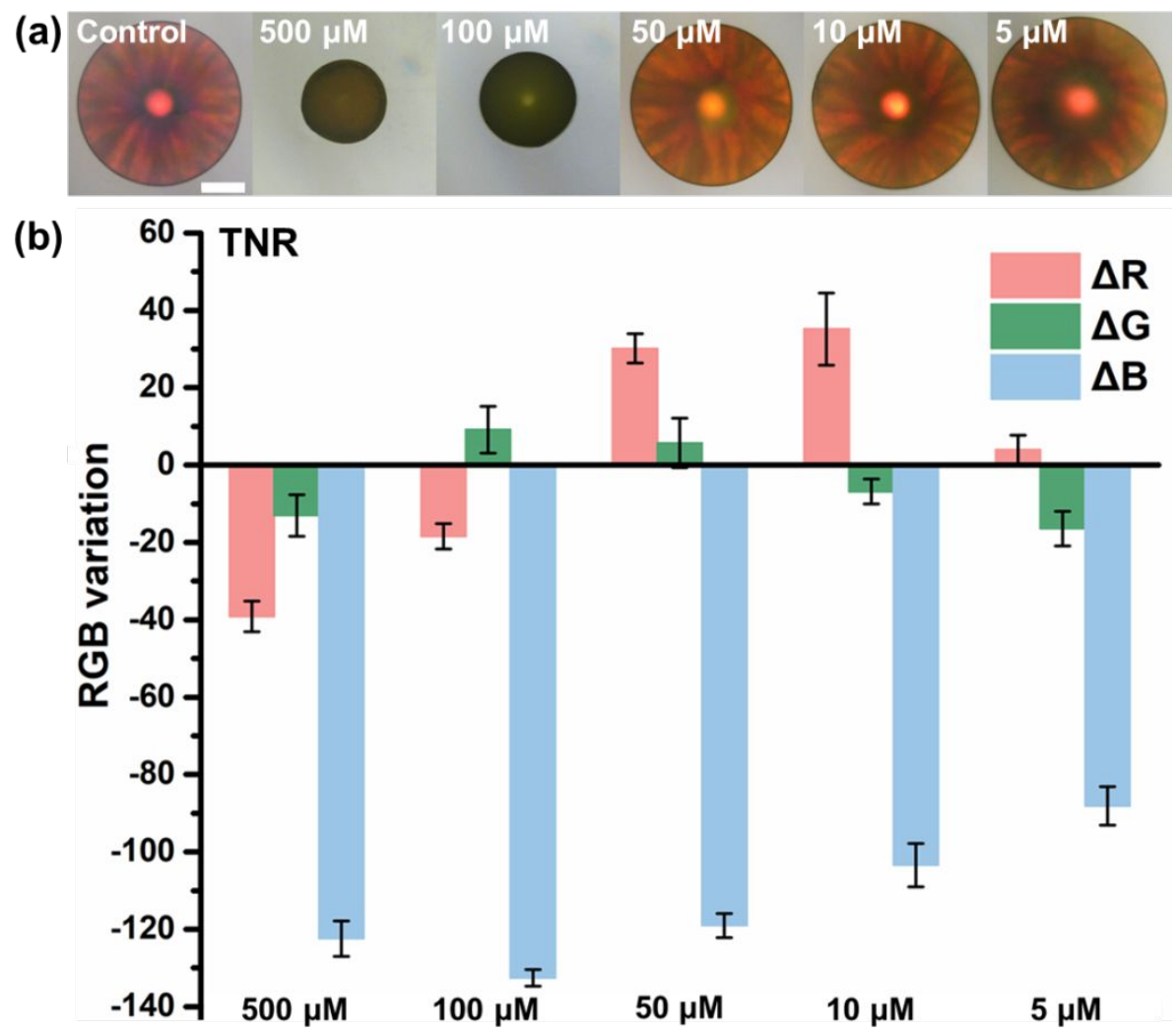

Figure S8. (a) The microscope optical images of the PIL spheres before and after binding TNR at different concentrations and (b)the histogram of corresponding $\Delta$ RGB data. The scale bar is $200 \mu \mathrm{m}$. 
(a)

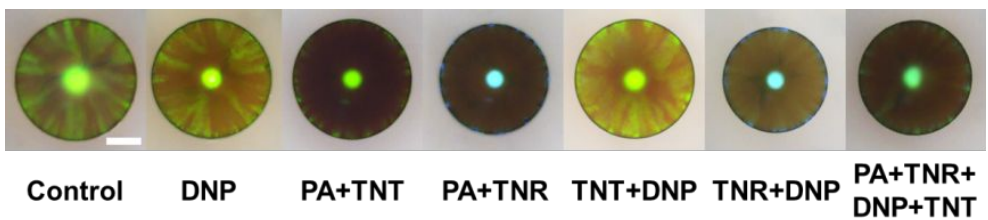

(b)

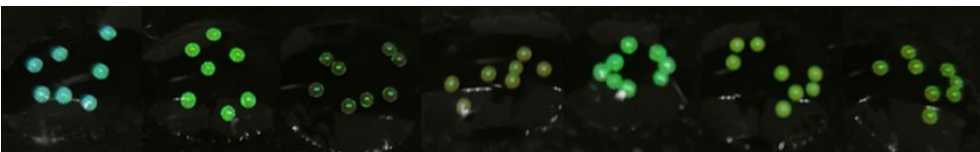

(c)

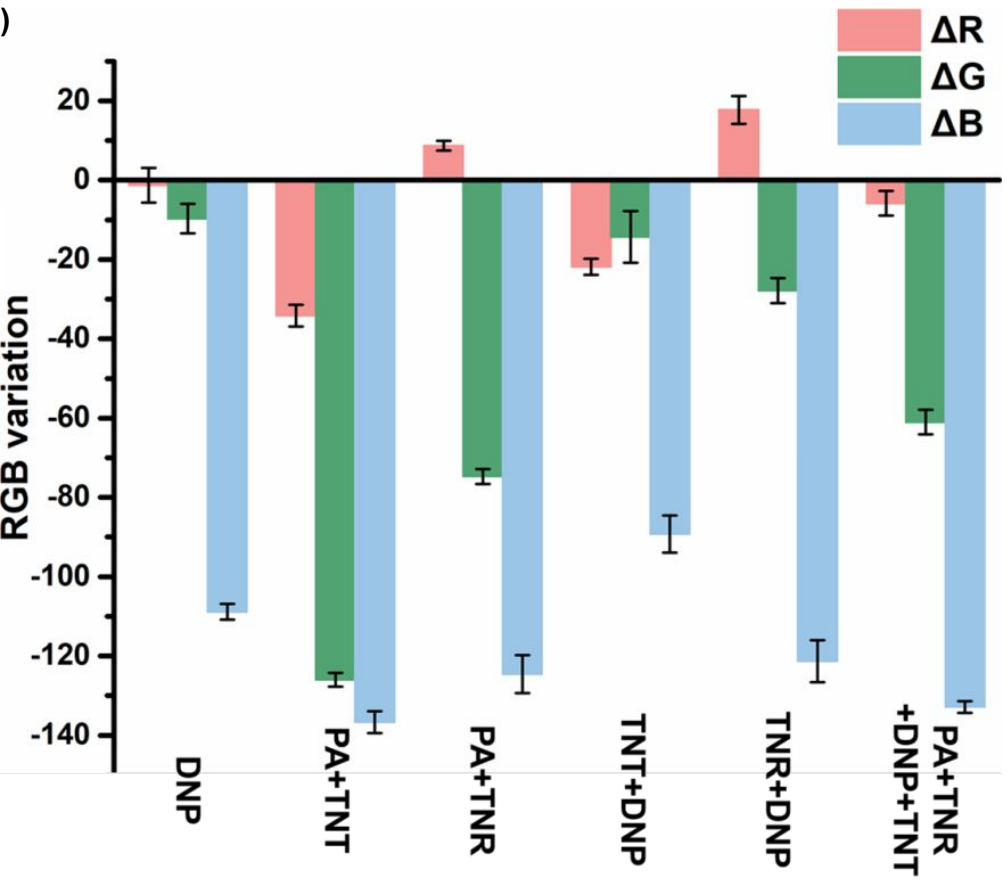

Figure S9. (a) The microscope optical images and (b) the photos of the PIL spheres before and after responding to DNP and five mixtures of explosives (c) the histogram of corresponding $\triangle \mathrm{RGB}$ data. The scale bar is $200 \mu \mathrm{m}$.

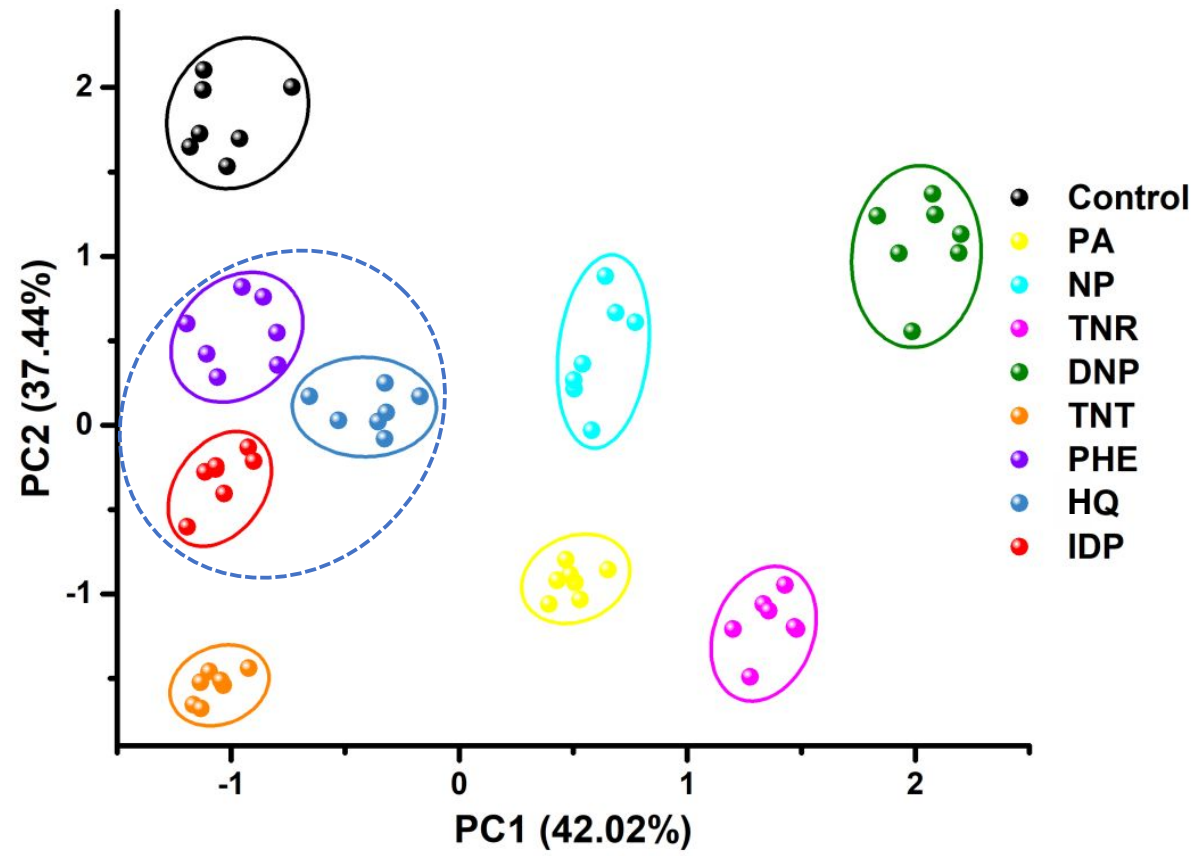

Figure S10. The PCA 2D score plot for discrimination of explosives and phenols. 
We also tried to distinguish different phenols from each other as well as the five explosives mentioned above. In our work, phenol (PHE), hydroquinone (HQ) and 4-iodophenol (IDP) were chosen to be tested (the concentration and solvent were same with explosive solution). As the PCA score plot shows (Figure S10), the three kinds of phenols were distinguished clearly. The various intermolecular interactions involved in the PIL skeleton of the spheres ensured the effective interaction between the sensing spheres and phenols. Notably, the clusters of PHE, HQ and IDP formed a larger cluster with distinct separation from the ones of explosives, as the dotted oval indicates. The reason lies in the difference of interaction between spheres and analytes: the phenols do not have nitro group, thus they lack the strong hydrogen bonding between nitro and urea groups. The result also proved that the non-nitro compound would not disturb the detection and discrimination for nitro explosives.

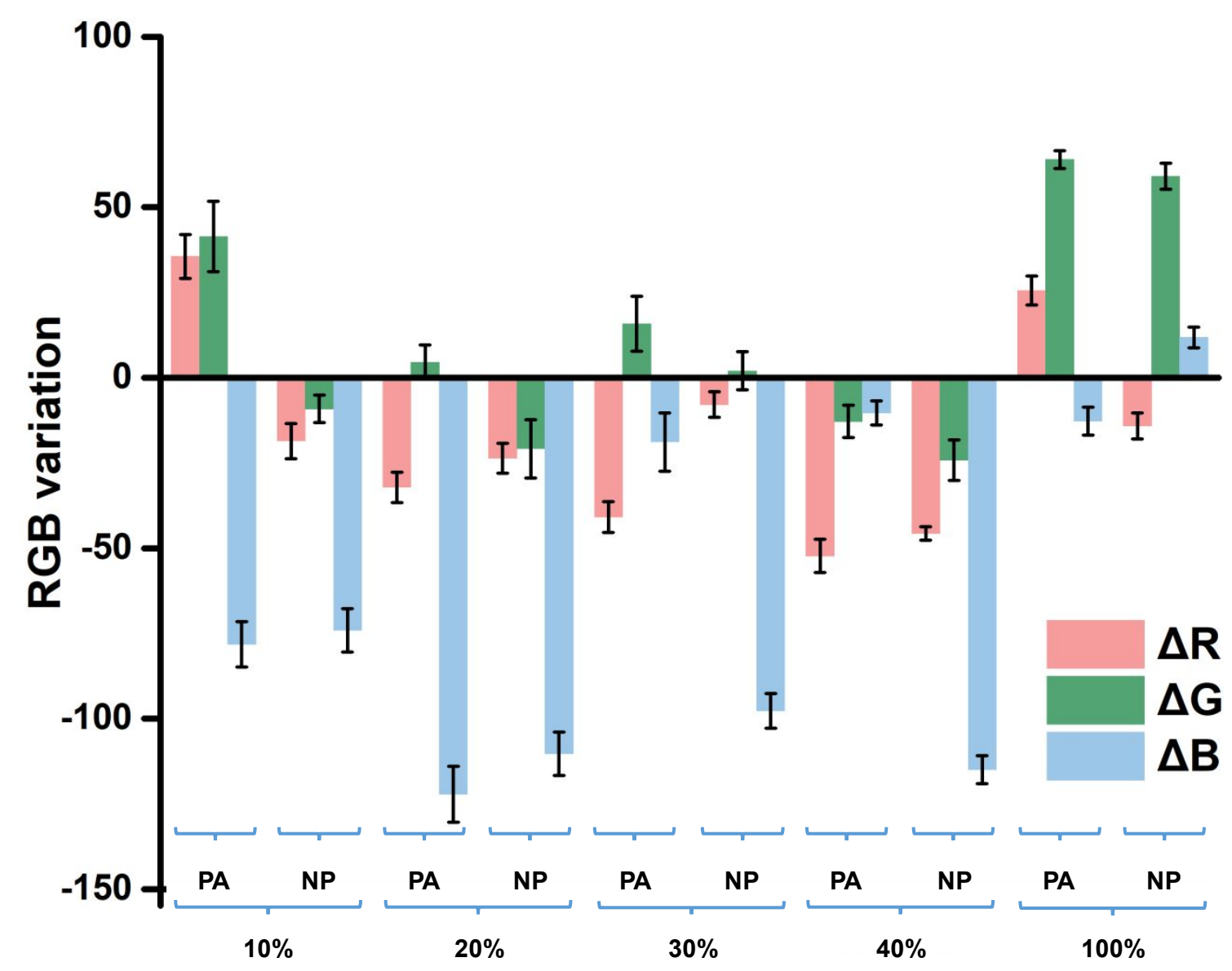

Figure S11. The histogram of corresponding $\triangle \mathrm{RGB}$ data of the PIL spheres with different degree of crosslinking. 


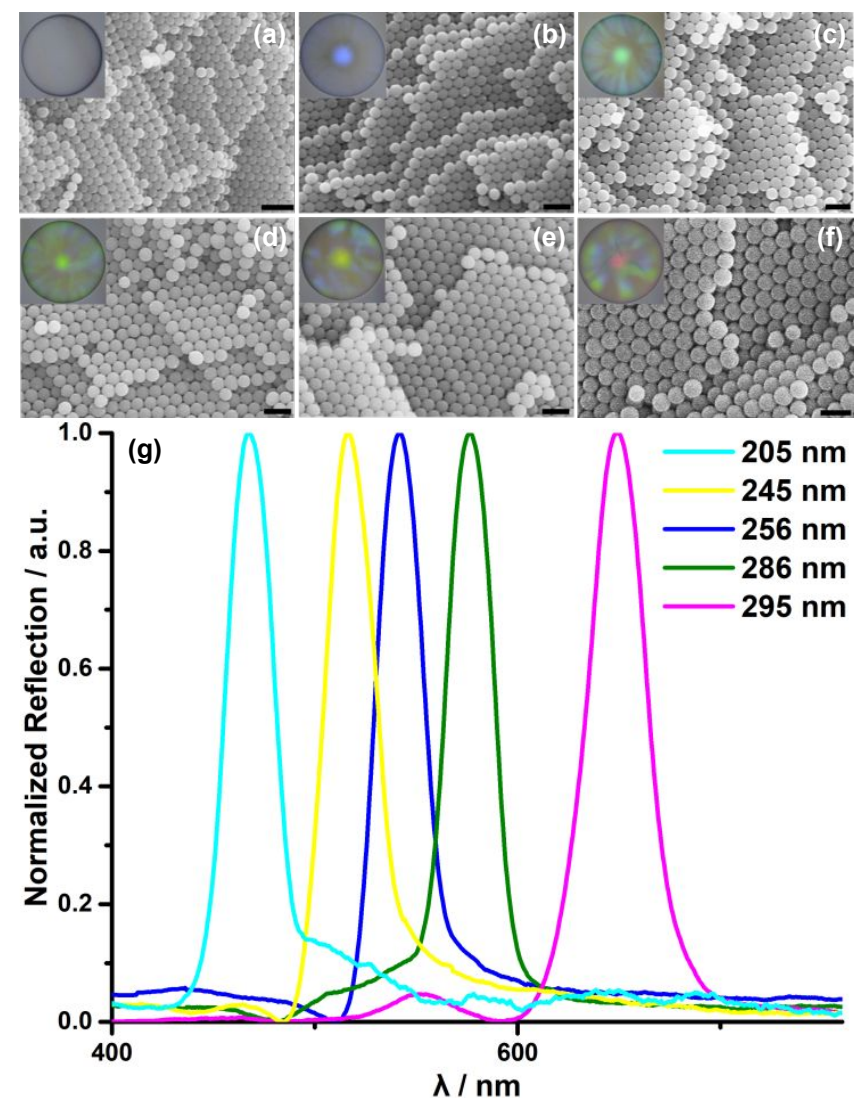

Figure S12 (a) - (f) The SEM images and (g) the reflection spectra of the photonic crystal sphere template used to prepared different PIL photonic spheres. The scale bars are $500 \mu \mathrm{m}$, and the insets are the optical images of the photonic crystal spheres.

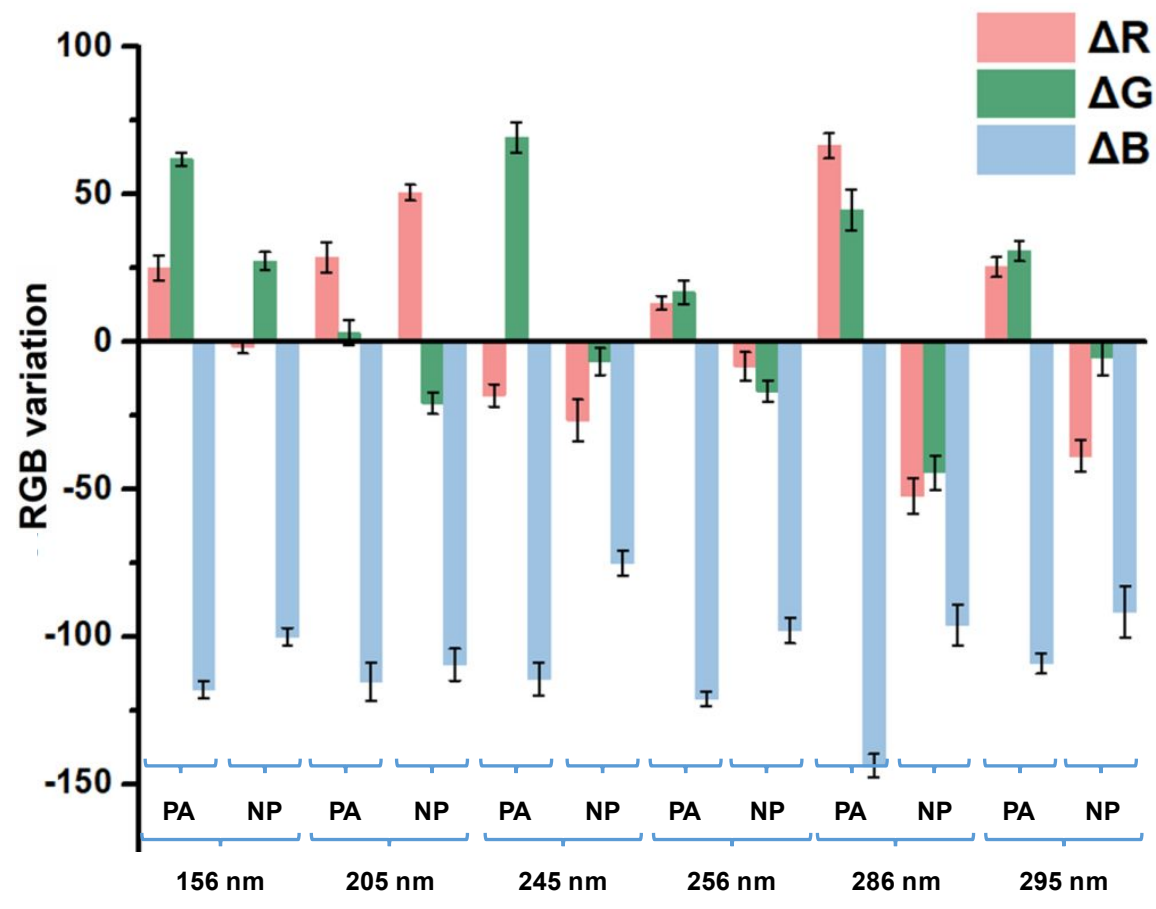

Figure S13 The histogram of corresponding $\triangle \mathrm{RGB}$ data of the PIL spheres generated from different photonic crystal templates after binding to PA or NP. 


\section{REFERENCES}

(1) Visser, A. E.; Swatloski, R. P.; Reichert, W. M.; Mayton, R.; Sheff, S.; Wierzbicki, A.; Davis, J. J. H.;

Rogers, R. D. Task-Specific Ionic Liquids for the Extraction of Metal Ions from Aqueous Solutions. Chem. Commun. 2001, 135-136. 